\title{
Possíveis Contribuições do Comparatismo para a Escrita de uma História da Literatura Latino-Americana
}

\author{
Posibles Contribuciones del Comparatismo para la Escrita de una \\ História de la Literatura Latinoamericana \\ Possible Contributions of Comparatism for the Writing of a History of \\ Latin American Literature
}

Marcelo de Andrade Duarte ${ }^{1}$

\begin{abstract}
Resumo
Este trabalho propõe pontuar algumas contribuições da crítica literária referente a utilização da Literatura Comparada, baseada nos preceitos da escola americana, para a escrita de uma História da Literatura Latinoamericana, visto que superaria análises positivistas de influências, possibilitando a superação da dependência cultural latino-americana, proposta essa já discutida por Candido, Santiago, Rama e Pizarro, entre outros críticos que serão citados ao longo do texto.
\end{abstract}

Palavras-Chave: Literatura Comparada; História da Literatura; América Latina.

\section{Resumen}

Este trabajo propone puntuar algunas contribuciones de la crítica literaria referente a la utilización de la Literatura Comparada, basada en los preceptos de la escuela americana, para la escrita de una Historia de la Literatura Latinoamericana, ya que superaría análisis positivistas de influencias, lo que permite la superación de la dependencia cultural de América Latina, esta propuesta ya discutida por Candido, Santiago, Rama y Pizarro, entre otros críticos que se citarán en el texto

Palabras claves: Literatura Comparada; Historia de la Literatura, América Latina.

\section{Abstract}

This paper proposes to point out some contributions of literary criticism regarding the use of Comparative Literature, based on the precepts of the American school, for the writing of a History of Latin American Literature, since it would overcome positivist analyzes of influences, making possible the overcoming of Latin cultural dependence American, a proposal already discussed by Candido, Santiago, Rama and Pizarro, among other critics that will be mentioned throughout the text.

Keywords: Comparative Literature; History of Literature; Latin America.

Não somos europeus ou americanos do norte, mas, destituídos de cultura original, nada nos é estrangeiro, pois tudo o é. A penosa construção de nós mesmos se desenvolve na dialética rarefeita entre o não ser e o ser outro" (SALLES GOMES, 1986, p. 88).

\footnotetext{
${ }^{1}$ Doutorando em Teoria da Literatura, Pontifícia Universidade Católica do Rio Grande do Sul (PUCRS). E-mail: marcelo.duarte.002@acad.pucrs.br. Trabalho apresentado no III Encontro Humanístico Multidisciplinar e II Congresso Latino-Americano em Estudos Humanísticos Multidisciplinares, Jaguarão/RS, Brasil, 2017.
} 
A origem da literatura comparada coincide com a própria área que ela estuda. Como o seu principal objetivo é a análise de duas ou mais literaturas, bastou a emergência delas para a manifestação do comparatismo. Assim, o nascimento da literatura grega e romana coincide com o da Literatura Comparada.

Embora tendo a existência de milhares de anos, o comparatismo surge como uma disciplina institucionalizada no século XIX, no contexto europeu, nomeada como Literatura Comparada. Nesse momento tinha como objetivo estabelecer a influência de autores, servindo como uma ferramenta para mostrar a força de um país em detrimento de outro.

Até meados do século XX a palavra-chave para compreensão da Literatura Comparada era influência, visando a afirmação de uma cultura nacional, intimamente ligada ao nacionalismo, devido a visão cosmopolita de alguns intelectuais franceses que introduziram a literatura comparada nas universidades francesas, entre eles Philarète Chasles e Jean-Jacques Ampére (cf. NITRINI, 2000).

Em Texto Fundadores, de Tânia Carvalhal e Eduardo Coutinho (1994), temos uma organização de ensaios críticos e teórico, com a participação de autores de diferentes países, que nos permitem a visualização da constituição e expansão do conceito de literatura comparada no mundo. Inicialmente, ela era utilizada como um meio de comparar literaturas de um mesmo país - às vezes de textos na mesma língua, mas de países diferentes. No entanto, Henry Remak (1994) pensa a literatura comparada de um modo mais abrangente, vendo-a como o estudo da literatura "além das fronteiras", seja de um país específico, ou de uma língua também específica. Remak pensa também na relação entre literatura e diferentes áreas do conhecimento como a pintura, escultura, arquitetura, música, filosofia, história, cinema etc. Percebe-se, então, que por tal definição Remak filia-se à Escola Americana, já que o pensamento da Escola Francesa está mais voltado para o que foi apresentado inicialmente nesse parágrafo.

Tal pensamento de Remak nos leva a pensar em um conceito operacional para a prática comparatista nos dias de hoje, pensando, principalmente, na interdisciplinaridade e na intertextualidade, visto que, em grande parte dos trabalhos acadêmicos dos dias de hoje, a literatura está comparada com as mais diversas expressões do conhecimento humano. Sendo assim, Tânia Carvalhal (2003) destaca que é necessário que o comparatista tenha domínio de, no mínimo, duas áreas do saber: a literatura e outra, seja a história, a sociologia ou as demais citadas anteriormente. A literatura comparada ao estabelecer-se como disciplina torna-se um método de análise da obra literária localizada em um contexto cultural, ou seja, suas relações com a sociedade como um todo, indo contra o que pensavam os formalistas russos, salvo 
exceções, para os quais os textos literários valiam-se por si, sem ser necessário analisar o contexto em que estavam inseridos.

Ao realizarmos essa contextualização histórica da prática comparatista, como campo epistemológico relacionado aos estudos literários, percebemos que desde sua origem há uma vinculação com diferentes áreas relacionadas à cultura. Na contemporaneidade, essa relação ampliou-se, pois ao "acolher a diversidade" (CUNHA, 2011) a literatura comparada generalizou-se, ou seja, todos os estudos literários tornaram-se interdisciplinares (cf. COUTINHO, 2011) dialogando com as mais diversas áreas do conhecimento, como afirmado anteriormente, o que pode ser comprovado ao analisarmos os anais dos encontros da Associação Brasileira de Literatura Comparada (ABRALIC).

Diante do exposto, este trabalho tem o objetivo de analisar os benefícios da utilização do método comparatista americano, também do latino-americano, para a escrita de uma história da literatura. Para isso, pontuaremos alguns estudos críticos, como os de Antonio Candido, Angel Rama e Silviano Santiago.

Representantes do pensamento da escola francesa, Pichois e Rousseau apresentam-nos a concepção pela qual era entendida a literatura comparada no século XX:

A literatura comparada é a arte metódica, pela busca de ligações de analogia, de parentesco e de influência, de aproximar a literatura dos outros domínios da expressão ou do conhecimento, ou então os fatos e os textos literários entre eles, distantes ou não no tempo e no espaço, contanto que eles pertençam a várias línguas ou várias culturas participando de uma mesma tradição, a fim de melhor descrevêlos, compreendê-los e apreciá-los. (apud CARVALHAL, 2006, p. 31)

Tal definição despreza um estudo das diferenças, interessando-se apenas pela aproximação de elementos de uma mesma tradição. Nesse conceito de tradição, a cronologia o texto que veio antes - é um parâmetro de análise que expressa superioridade e originalidade. Essa tradição historicista foi introduzida, especialmente, por Paul Van Tieghen - precursor da escola francesa, com a publicação de La littérature comparée (1931).

Pensando na literatura comparada no Brasil, em certo momento, alguns críticos ao utilizarem-se de um procedimento comparatista próximo às concepções clássicas da "linha francesa", como o exposto por Pichois e Rousseau, houve um reforço da dependência cultural.

Em "Literatura e Subdesenvolvimento", Candido discute pontualmente a questão da dependência cultural ${ }^{2}$ na América Latina e comenta: "um problema que vem rondando este ensaio e lucra em ser discutido à luz da dependência causada pelo atraso cultural é o das

\footnotetext{
2 “derivação do atraso e da falta de desenvolvimento econômico” (CANDIDO, 1989, p. 156).
} 
influências" (1989, p. 151). Com essa citação de Cândido, percebemos que tanto os estudos da dependência cultural como a literatura comparada, baseada nos preceitos franceses, partem de discussões apenas das influências. Nesse ensaio, Candido metaforiza a literatura latinoamericana como um "galho" das metropolitanas, de certa forma, aproximando-se da busca de "graus de parentesco" indicados por Pichois e Rousseau.

Assim, cabe-nos questionar até que ponto, a crítica comparatista brasileira e latinoamericana não reforçava a condição de subalternidade desse lócus de enunciação. Ou, ainda, como os críticos buscavam romper com ela, com estudos que discutissem a literatura latinoamericana de dentro, sem ver a questão da influência fechada em si, sem fazer juízos de valor de literatura maior e menor, mas indo além disso. Estudando, por exemplo, as influências da cultura indígena, como propôs Rama e Pizarro.

Destaca-se que a crítica após os 60 buscaram a resolução das discussões sobre dependência cultural e influências. Podemos interligar essa preocupação da crítica com o fato de que também a partir dos anos 50 e 60, um congresso de literatura comparada coloca em discussão a hegemonia dos estudos comparados da escola francesa, nesse contexto, o congresso realizado em Chapel Hill, no ano de 1958, estabelece um marco da ascensão dos estudos de Literatura Comparada nos Estados Unidos. No congresso mencionado, uma das principais falas foi realizada por René Wellek - teórico que estrutura a Teoria da Literatura como uma disciplina, representando uma ruptura com a literatura comparada tradicional:

A tentativa de restringir a "literatura comparada" a um estudo de "comércio exterior" entre literaturas é certamente infeliz. A literatura comparada seria, em seu objeto de estudo, um conjunto incoerente de fragmentos não relacionados: uma rede de relações constantemente interrompidas e separadas dos conjuntos significativos. O comparatista qua comparatista, neste sentido limitado, só poderia estudar fontes e influências, causas e efeitos, e seria impedido, até mesmo, de investigar uma única obra de arte em sua totalidade, uma vez que nenhuma obra pode ser inteiramente reduzida a influências externas ou considerada um ponto irradiador de influência sobre países estrangeiros apenas. (WELLEK apud CARVALHAL e COUTINHO, 1994, p. 109).

Este estudioso ${ }^{3}$ sugere, então, que a literatura comparada represente uma leitura profunda de um texto sem considerar apenas os fatores extratexto, mesmo considerando o contexto um complemento importante nos estudos literários. No entanto, há uma censura aos estudos de "comércio exterior", de análises de fontes e influências, abrindo o campo de estudos da literatura comparada, procurando um equilíbrio entre a análise crítica do texto e o elemento histórico. Essa ampliação e a conceituação da proposta da escola americana é

\footnotetext{
${ }^{3}$ Influenciado pelo New Criticism e pela Fenomenologia.
} 
consolidada pelo estudo de Henry Remak, já comentado no início deste texto, de pensar a literatura em relação com outras áreas: filosofia, sociologia, pintura etc.

No prefácio de Formação da literatura brasileira, Candido compara a literatura brasileira com as grandes literaturas (europeias), afirmando que a brasileira seria inferior “nossa literatura é pobre e fraca. Mas é ela, não outra que nos exprime.” (1997, p. 10) também que "nossa literatura é galho secundário da portuguesa" (1997, p.9) também em "Literatura e subdesenvolvimento" há essa metáfora arbórea "as nossas literaturas latino-americanas são basicamente galhos das metropolitanas" (1989, p. 151). Quando faz essas constatações, Candido instaura a ideia de parentesco, de influência, com a relação comparatista sob um olhar colonizado de inferioridade, um conceito de literatura altamente clássico que não considera as diferenças, apenas coloca duas literaturas lado a lado para inferiorizar uma delas, nesse caso a brasileira em detrimento das "altas literaturas" europeias.

Ao traçar um paralelo entre as literaturas portuguesa e brasileira, Candido diz que elas se ligam de maneira tão íntima que são uma "literatura comum". Termo esse que se aproxima de dois conceitos caros ao comparatismo francês: literatura geral, Weltliterature, de Goethe, e o também literatura geral, de Paul Van Tieghem. No entanto, apesar de utilizar um conceito tão delimitador para a tentativa de superação de uma dependência cultural, Candido expande o uso da literatura comparada em Formação da literatura brasileira, pois não se mantém na discussão de fontes, escrevendo um livro que reflete a formação da sociedade e de uma cultura brasileira, e também rediscute a própria crítica brasileira dos que o antecederam. Assim, Candido vai além dos estudos de linhagem predominantes nas Histórias da Literatura ${ }^{4}$ e contribui para a realização de um desejo de uma literatura e cultura próprias do Brasil, isso por um viés próximo do comparatismo americano.

Antonio Candido contribui, sobremaneira, com a Literatura Comparada na América Latina, principalmente, com sua formulação dialética entre o localismo e cosmopolitismo, cuja análise não cai em um nacionalismo que ignora os problemas de influência, imitação e cópia da literatura de um país politicamente, economicamente e culturalmente dependente dos outros. Quanto a questão da influência, Candido reconhece nossa dependência cultural até certo momento, mas com o passar dos anos, nossa literatura passa a se tornar original, a partir do ponto que reconhece o vínculo intrínseco que a une com as europeias, colocando-nos lado

\footnotetext{
${ }^{4}$ Que até o momento, com os críticos românticos, centravam seus interesses na constituição de um corpus que buscava a existência de uma literatura que poderia se chamar brasileira. Nessa fase, marcada por um critério puramente quantitativo, esses críticos, conforme Antonio Candido, comprometiam-se em organizar os "florilégios", "panteões" dos poucos textos disponíveis. A partir desse trabalho dos críticos românticos, outros iniciaram a elaboração de histórias da literatura.
} 
a lado com elas. Não tendo um conceito positivista de influência, mas como algo recíproco em que há uma dialética entre imposição e adaptação cultural, de cópia e rejeição. Mediante esse método e de sua proposta da literatura como sistema, integrando a sociedade, Candido elabora um estudo comparatista independente das demais tendências, distante, principalmente, da escola francesa.

Silviano Santiago mantém o método crítico e metacrítico elaborado por Antonio Candido, inclusive rediscutindo ideias desse em "O entre-lugar do discurso latino-americano". Em tal texto, também por um método influenciado pelo comparatismo americano e pelos estudos culturais (que tiveram sua origem em ambiente americano), já que escreveu esse texto quando estava como professor visitante na Universidade Estadual de Nova York, o autor faz uma revisão crítica do conceito de fontes e influências e questiona o papel do intelectual latino-americano. Silviano Santiago (junto com Haroldo de Campos e Roberto Schwarz e outros) contribui também para a implantação de uma literatura comparada renovada e independente das escolas europeias.

Santiago propõe que estamos em um entre-lugar não somos essencialmente cópia nem inovação, um lugar híbrido entre colonizador e colonizado. Em Ricardo Piglia temos uma proposta próxima a de entre-lugar: "Hay que tener un ojo puesto en la inteligência europea y el otro puesto en las entrañas de la patria" (1991, p. 61), ou seja, temos de ter um olhar “estrábico". Resulta disso uma contribuição da América Latina para toda a cultura ocidental que "vem da destruição sistemática dos conceitos de unidade e de pureza: estes dois conceitos perdem o contorno exato de seu significado, perdem seu peso esmagador, seu sinal de superioridade cultural" (SANTIAGO, 1978, p. 18). A América Latina impõe seu reconhecimento na cultura ocidental através da transgressão da norma, da transfiguração de elementos exportados pelos europeus.

Assim como Candido e Santiago, Angel Rama também renova o comparatismo, estabelecendo uma identidade latino-americana a ele, quando propõe que seja substituído o método europeu da historiografia literária que ligava a identidade com a nação integrada em torno de uma língua, de uma história e de um povo em comum, pois a América Latina não poderia pertencer a essa realidade. A proposta transcultural das comarcas de Rama, propõe que a literatura latino-americana seja pensada em suas relações culturais, indo além das fronteiras impostas pela geografia política, por um comparatismo cultural que integrasse também a cultura indígena, rompendo com a unidade e propondo um modelo plurisistêmico.

Muito inspirada pelas ideias de Rama, Ana Pizarro também propõe uma nova visão da crítica literária comparatista da América Latina. Para a estudiosa chilena, não pode-se 
trabalhar com qualquer método comparativo positivista, dada tamanha pluralidade cultural da América Latina, assim, desenvolve um estudo das relações com a Europa e as "pequenas" literaturas, como as indígenas, por exemplo. Aproximando-se da proposta de Réne Etiemble que ao criticar a hegemonia dos estudos de influência da França, desenvolve a ideia que qualquer literatura, por "menor" que seja, pode influenciar e ser influenciada.

A partir de Candido, o pensamento latino-americano comparatista esteve preocupado com a inclusão de literatura num contexto mais amplo da cultura. As propostas de investigação de Angel Rama e Ana Pizarro, sugerem uma reflexão dos processos de transculturação entre Europa e América Latina, questionando um cânone eurocêntrico, refletindo as relações entre a literatura latino-americana e outras formas culturais, tais como a literatura oral, o folclore e todas as chamadas literatura "populares". Essas preocupações proporcionam uma aproximação entre a literatura comparada da América Latina com os estudos culturais e apresentam um interessante método comparatista transdisciplinar que vê a literatura sempre em diálogo com outros processos culturais, uma prática discursiva "contaminada" por outros âmbitos do saber, que pode auxiliar uma possível escrita de uma história da literatura da América Latina.

\section{Referências}

CANDIDO, Antonio. A educação pela noite e outros ensaios. São Paulo: Ática, 1989. Formação da Literatura Brasileira: momentos decisivos. Belo Horizonte: Editora Itatiaia Ltda., 1997.

CARVALHAL, Tania Franco. O próprio e o alheio: ensaios de literatura comparada. São Leopoldo: UNISINOS, 2003.

Literatura Comparada. 4 ed. rev. e ampliada. São Paulo: Ática, 2006.

COUTINHO, Eduardo e CARVALHAL, Tania Franco (Org.). Literatura comparada: textos fundadores. Rio de Janeiro: Rocco, 1994.

COUTINHO, Eduardo. Literatura comparada na América Latina: ensaios. Rio de Janeiro: EdUERJ, 2003.

CUNHA, João Manuel et. al. (org.). Literatura: crítica comparada. Pelotas: EDUFPel, 2011.

NITRINI, Sandra. Literatura Comparada. São Paulo: EDUSP, 2000.

PIGLIA, Ricardo. Memoria y Tradición. Congresso ABRALIC. Belo Horizonte: UFMG, 1991. p. 60-66. 
PIZARRO, Ana (Org.). América Latina: palavra, literatura e cultura. Campinas: UNICAMP, 1993.

RAMA, Ángel. La ciudad letrada. Santiago: Tajamar, 2004.

Transculturación narrativa en América Latina. México: Siglo Veintiuno, 2004.

SALLES GOMES, Paulo Emilio. Cinema: trajetória no subdesenvolvimento. São Paulo: Paz e Terra, 1986. 